\title{
Science and Engineering Education in Europe
}

\section{Gertrud Humily}

THIS PAPER ADDRES SE S diversity in science education in Europe. I would like to give you first a global overview of education in engineering and sciences in our countries and then present two European models for global education for engineers and scientists that are becoming increasingly important components of their curricula.

In addition to university studies in science leading to traditional degrees, Europeans offer two types of studies for engineers: (I) a practice oriented degree, which includes compulsory internships in industry, and is usually completed in a shorter cycle of studies, close to the American bachelor's program, and (2) a longer program, leading to an engineering degree that can be compared to the U.S. Master's in Science and/or Engineering. In most European countries these two types of education take place in different institutions of higher education, with no easy transition from one type to the other; if attempted, the student loses at least one academic year. The reason for the difficult transition from one type to another is obvious: the approach to engineering education is completely different in both cases. While the short cycle trains more practice-oriented engineers for industry, the long cycle prepares research-oriented engineers, scientists or top managers who in France are called "generalists." Basic science is very important from the beginning and takes a big space in the latter model, while a more practical approach allows students of the shorter cycle to be immediately ready to work in industry.

1. SCHEME: ENGINEERING DEGREE OR TITLE

2. SCHEME:PRACTICE-ORIENTED ENGINEERING PROGRAMS

3. ENGINEERING STUDIES IN DIFFERENT EUROPEAN COUNTRIES 
The average length of study is six to seven years after high school for the long cycle, and three to five years for the shorter cycle. Coming from France, I am especially interested in presenting the French system as clearly as possible, but I would need more time to do that.

\section{LES GRANDES CATEGORIES D'ECOLES D'INGENIEURS}

I should point out that there are about two hundred different ways of becoming an engineer and that the status of engineer, professionally and socially speaking, is considered extremely high for historical reasons, and because engineering schools are very selective in their admissions. This is not the case in Germany and even less so in the United Kingdom. The richness of the French programs is certainly one of the biggest advantages for global education, but there is the handicap of the very theoretical basic education, which creates problems for the integration of foreign students into the traditional curriculum. Therefore, innovative schools offer more and more programs that are tailor-made to the different levels of students from abroad, who must increasingly adapt to the model of the European engineer.

As you can easily understand, it is difficult for European education to open up its programs to European neighbors, in order to create a "European label," without losing its own characteristics and traditional national approaches. Programs launched by the European Union's Commission in Brussels-you may be familiar with the ERASMUSSOCRATES programs or the COMETT-LEONARDO programsprovided an incentive to work closer together and create more European unity. When an American student goes for a Bachelor's at Texas A\&M or for a Master's at MIT, he or she crosses almost a continent but is still in his or her country, able to communicate in the same language and settle without any major problems. That is not the case for a French student desiring to take a substitution semester or a year of specialization at the University of Karlsruhe, only about a thirtyminute drive from the French boarder: the language, the culture, and the study programs have completely changed, and the student would have almost the same "cultural shock" as if he or she were going to Moscow or Oslo. 
Global education is also urgent for meeting the needs of industry, as nearly every European small-and middle-sized firm approaches more and more the European market, and thus has a greater need for globally educated engineers and scientists. Because of the difficult economic situation in general, firms are no longer able to educate their young staff members through their own expensive continuing education programs. For these reasons, European industrialists are interested in hiring globally trained engineers and almost always give preference to young candidates with experience abroad. I could give you many examples of young engineers who were hired not because of their excellent national academic education, but because of the international experience they could include in their resume.

With regard to acquiring this experience, I would say that the European networks which have been established with financial support from Brussels are working extremely well, and the links made through bilateral agreements are the key to the success we are having on our side of the Atlantic. You can find all types of cooperation and exchanges of faculty, students, staff, and researchers; this has contributed to creating a European diversity during the past ten years that we want to extend now to our American friends.

Before showing you briefly two different types of existing programs, I would like to mention that in this country "diversity" would probably mean more the integration of underrepresented populations in engineering and science education. This varies a great deal from one European country to the other, for historical and political reasons. I only would point out that the problem of female engineers is less apparent during the education and recruitment phase, and much bigger in their subsequent careers in industry. In the former East Germany, the reintegration of so many female engineers is a major problem because of unemployment and other reasons.

To sum up this very incomplete picture of the European education landscape, you might remember the very different systems generated by the technological and political developments in these countries. As we all live in a technical environment, forgetting more and more our original natural milieu, we have to continuously adapt to rapid technological progress. The narrow technical engineering science background is quickly becoming obsolete, and there is now a greater 
need for engineers, who add value through human, social and legal sciences in order to both manage and criticize technological procedures. Diversity, transparency, and permeability of educational systems should make it easier to reach this ideal profile of the engineer for the year 200o. Well-framed global programs are tools to obtain this profile or at least to get closer to it.

Below, I present two of the many existing programs started in Europe: both consist of networks of universities and industry that might serve as interesting models of umbrellas for bilateral agreements, which allow for greater formal cooperation and better mutual knowledge in specialized fields between partner universities.

1. THE EURONATIONAL CERTIFICATE (ENC) PROGRAM

The purpose of the Euronational Certificate is not to accredit the level of studies, although it is awarded to students who have completed at least two years of study in a technological field. We are now reaching a significant number of certificates (about 130), and are working on the proper label in Europe. We would like to extend this program to American students, who would obtain a certificate as proof of their European academic stay, a useful addition to their American degree that they could show to industries.

2. THE AMERICAN EUROPEAN EXCHANGE IN ENGINEERING PROGRAM (AE3) PROGRAM

In November 1993, a group of U.S. engineering schools met at the University of Cincinnati to establish the AE3 Consortium on the U.S. side. The program is currently coordinating a consortium of 27 European member schools and about 20 U.S. schools. It is now in its first year of regular exchange, involving 100 students from the United States, France, Germany, Austria, and Denmark. While a number of bilateral programs and other agreements link individual U.S. and European universities, there was previously no national program through which U.S. universities could send their engineering students to European institutions for a semester or year of study and supervised practical training, with structures evaluated and validated for American academic credit. In addition to the technical course work and internship, the program includes a language preparation period to ensure that U.S. students have the linguistic skills to function effectively in the host country. An intensive orientation period, lasting four to six 
weeks in the host country, improves the linguistic level of the students and introduces them to the culture, academic milieu and industrial context of the country where they are to be placed.

Selection of the students is done by the home country faculty, typically at the end of the second year of college. Each participating school agrees to accept without additional tuition expense, approximately an equal number of students in order to balance over a three-to-five-year period the number of students they send to the other country. American students are funded through NSF and the ATT Foundation, and an application to FIPSE was made which will, one hopes, also be successful.

The United States $\mathrm{AE}_{3}$ consortium is administered by the Institute for International Education (IIE) in New York and on the European side by the Global Education for European Engineers and Entrepreneurs (GE4) Secretariat, for which I am responsible in Paris. This exciting enterprise will be extended to other European countries, to Asia, Australia, and South America. Furthermore, we are already working on the next phase, which will be the creation of a Master's and predoctoral program with a period of time spent abroad in selected academic institutions or in participating industries, to carry out a part of the thesis or research project or even to have the opportunity to follow some specialized courses.

Note

The Executive Director for International Education has responsibility for the five institutions under the supervision of the Department of Defense: the Ecole Polytechnique; ENSTA, ENSAE, ENSICA (Toulouse) and ENSIETA (Brest). 